\title{
A Method of Calculating the Bearing Capacity of Sand Pile Composite Foundations in a Mucky Soil Layer Considering Consolidation
}

\section{Peishuai Chen ( $\sim$ ps.chen@qq.com )}

School of Highway, Chang'an University, Xi'an 710064, China

\section{Huiwu Luo}

CCCC Second Harbor Engineering Company Co.,Ltd.

\section{Dejie Li}

CCCC Second Harbor Engineering Company Co.,Ltd.

\section{Enlong Liu}

College of Water Resources and Hydropower, State Key Laboratory of Hydraulics and Mountain River Engineering, Sichuan University, Chengdu 610065

\section{Benliang Yang}

CCCC Second Harbor Engineering Company Co.,Ltd.

\section{Research Article}

Keywords: Sand compaction pile, Void ratio increase, Water content increase, Bearing capacity of foundation, Large caissons

Posted Date: January 19th, 2021

DOl: https://doi.org/10.21203/rs.3.rs-145083/v1

License: @ (i) This work is licensed under a Creative Commons Attribution 4.0 International License. Read Full License

Version of Record: A version of this preprint was published at Scientific Reports on August 20th, 2021. See the published version at https://doi.org/10.1038/s41598-021-95678-0. 
A Method of Calculating the Bearing Capacity of Sand Pile Composite Foundations in a

2 Mucky Soil Layer Considering Consolidation

3 Peishuai Chen ${ }^{\mathrm{a}, \mathrm{b}}, \quad$ Huiwu Luo ${ }^{\mathrm{b}}$, Dejie Li ${ }^{\mathrm{b}}$, Enlong Liu ${ }^{\mathrm{c}}$, Benliang Yang

$4 \quad$ aSchool of Highway, Chang'an University, Xi'an 710064, China

$5 \quad{ }^{b}$ CCCC Second Harbor Engineering Company Co.,Ltd., Wuhan, 430040, China

$6 \quad$ College of Water Resources and Hydropower, State Key Laboratory of Hydraulics and Mountain

$7 \quad$ River Engineering, Sichuan University, Chengdu 610065, China

8 The number of words of the main text is 4844.

9 Abstract: In engineering practice, the measured bearing capacity of a sand pile composite 10 foundation in a mucky soil layer is much larger than the design value. Based on the sand pile 11 construction and the load application process, a method of calculating the bearing capacity of the 12 foundation based on the effective stress was proposed. Cavity diameter expansion in sand pile 13 construction was simplified into a planar problem, and the cavity expansion theory was used to 14 establish the expression of the rate of displacement and the horizontal stress increase. Based on 15 the $\mathrm{e}-\mathrm{p}$ curve and the calculation of the degree of consolidation, the relationships between the 16 horizontal and vertical effective stress and the void ratio were obtained. According to the close 17 relationship between the bearing capacity of the foundation in a mucky soil layer and the water 18 content, an expression describing the relationships between the bearing capacity of the foundation, 19 effective stress, void ratio, and water content was established. For the temporary engineering 20 foundation treatment project, which needs a high bearing capacity but allows large foundation 21 deformation, the design of sand pile composite foundations uses these relationships to take the 22 consolidation effect of mucky soil into consideration, thereby reducing the replacement rate and 23 lowering the construction cost. 
24 Key words: Sand compaction pile; Void ratio increase; Water content increase; Bearing capacity

25 of foundation; Large caissons 


\section{Introduction}

27 Large caissons are widely applied in bridge tower foundations and anchor foundations because they can provide reliable bearing capacity and stability ${ }^{1}$. Since a large caisson has a large dead load, damage or rapid subsidence of an untreated superficial foundation is likely to occur under the dead load of the caisson. Therefore, the original foundation needs to be treated to ensure the smooth construction of the caisson. According to the construction technology of the caisson, the foundation reinforcement material needs to be excavated gradually with the sinking of the caisson, so the sand pile composite foundation is the preferred scheme.

The Wufengshan Yangtze River Bridge is part of the Lianzheng railway crossing Yangtze river control project (see Fig.1). Its north anchorage of the large caisson foundation is the world's largest land open caisson with a length of $100 \mathrm{~m}$ and a width of $70 \mathrm{~m}$. A plate load test was carried out before the foundation of the North Anchorage Caisson began to sink, the results of which show that the measured bearing capacity is much larger than the design value. The excessively strong bearing capacity of the foundation not only causes resources to be wasted but also hinders the sinking of the caisson, which leads to more soil support being excavated to increase the large caisson sinking coefficient, increasing the risk of the cracking of the caisson as the support span becomes larger. The foundation treatment of the North Anchorage Caisson of the Wufengshan Yangtze River Bridge is designed according to the requirements of the permanent works. However, the bearing capacity of foundation is too high to prevent the open caisson sinking, which causes the structure stress of the large caisson to exceed the permissible value. Sand pile composite foundations have been used for a long time, and many in-depth researches have been conducted in this field. Two main factors affect the bearing capacity of a sand pile composite foundation: the construction of sand compaction piles and the overburden load. First,

Authors: Peishuai Chen, Huiwu Luo, Dejie Li, Enlong Liu, Benliang Yang. Corresponding author: Peishuai Chen. (email: ps.chen@qq.com) 
the construction of sand compaction piles leads to an increase in the bearing capacity of the soil

50 foundation between the piles. Butterfield ${ }^{2}$ first proposed the use of the cylindrical cavity

51 expansion under plane strain conditions to solve the problem of pile penetration. Vesic ${ }^{3}$

52 summarized the solution to the expansion of spherical cavities and cylindrical cavities and also

53 extended the cavity expansion theory to compressible soil to obtain the calculation equation of

54 the ultimate bearing capacity of the soil. Randolph ${ }^{4}$ applied the cavity expansion theory and finite

55 element analysis to analyze the stress generated by the piles in the clay and the subsequent

56 consolidation. Yu and Houlsby ${ }^{5}$ used the finite element method and cavity expansion theory to

57 analyze the load of expansive soil. Collins ${ }^{6}$ used the critical state model to derive the large strain analytical solution for undrained cylindrical and spherical cavity expansion. According to the cavity expansion theory and the strain path, $\mathrm{Zhou}^{7}$ proposed a method of calculating soil

60 displacement around non-circular piles in clay. Second, the load from the top compacts the soil,

61 increasing the bearing capacity of the foundation. When treating the soft soil foundation using the

62 drainage consolidation method, Barron ${ }^{8}$ and Richart ${ }^{9}$ applied two assumptions, i.e., free strain

63 and equal strain, to solve the radial drainage degree of consolidation of the soil layer, believing

64 that when the drain spacing ratio was greater than five, the average degrees of consolidation of

65 the foundation obtained by the above two calculation methods were very close. Onoue ${ }^{10}$

66 considered the analytical solution to sand well consolidation with smearing. Olson ${ }^{11}$ and Lekha ${ }^{12}$

67 proposed analytical solutions to sand well consolidation under variable load conditions. There is

68 a unique relationship between the effective stress and the void ratio of saturated soft clay, and it is

69 independent of the conditions of drainage ${ }^{13}$. The bearing capacity of the foundation is related to

70 the cohesion $c$, the internal friction angle $\phi$, and the uniform load $q$ acting on both sides of the

71 foundation ${ }^{14}$, but the change of the cohesion and the internal friction angle caused by the increase

\section{4}

Authors: Peishuai Chen, Huiwu Luo, Dejie Li, Enlong Liu, Benliang Yang.

Corresponding author: Peishuai Chen. (email: ps.chen@qq.com) 


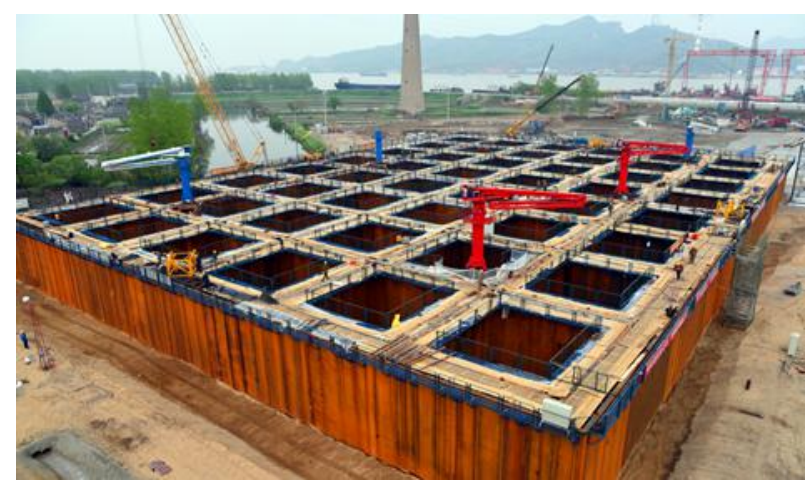

Fig. 1 Wufeng mountain Yangtze river bridge's north anchorage caisson

Current research indicates that sand pile construction and preloading of piles can increase the bearing capacity of the foundation. In engineering applications, foundation settlement tends to be the key indicator of whether the design and the bearing capacity can meet the needs easily. Thus, the improvement of the bearing capacity of a foundation has little effect on the design of foundation treatment. For large caisson constructions, however, the foundation treatment is a temporary work, and the bearing capacity is the key indicator, so foundation settlement is generally paid little attention. The construction of the caisson in the pre-fabrication process takes a relatively long time, which is the process of applying loading step by step. The foundation produces large consolidation deformation because of the additional load and the drainage channel in the sand pile. As a result, the measured bearing capacity of a sand pile composite foundation is much larger than the design value. In this study, the construction and preloading process of sand piles were systematically studied. Moreover, an expression describing the relationships between the bearing capacity of the foundation, effective stress, void ratio, and water content was

88 formulated to optimize the design.

\section{Increase of Foundation Stress Induced by Sand Pile Construction}

90 Pipe casing is often applied in the construction of sand piles, that is, the lower-end discharge 
method. During the sand pile construction, a cavity is made through the pipe casing, the lower

92 part of the casing is closed, and the cavity is expanded in the mucky soil layer by mechanical

93 static pressure and vibration. Then, as the casing is lifted, the valve at the bottom of the casing is

94 automatically opened, and the cavity is filled with sand to form the sand pile. This process can be

95 simplified into cavity expansion. In this study, this theory was used to calculate the increase of

96 the bearing capacity of the foundation in the mucky soil layer caused by sand pile construction.

\section{$97 \quad 2.1$ Cavity Expansion Theory and Basic Assumptions}

98

99

100

101

102

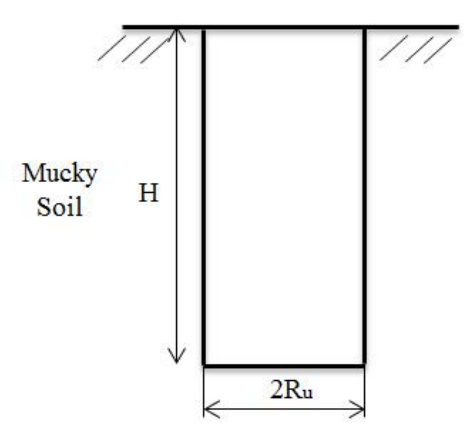

After cavity expansion

Fig. 2 Cavity expansion model

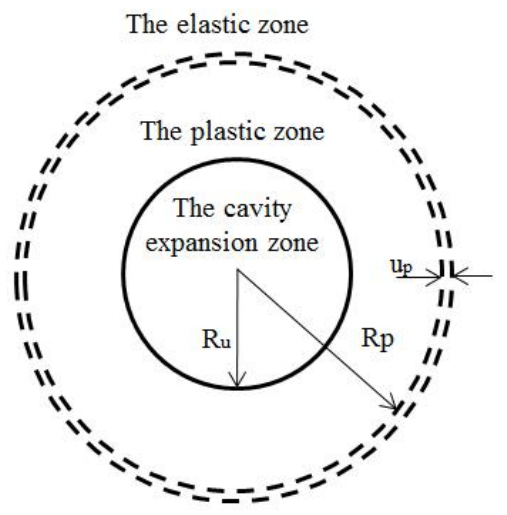

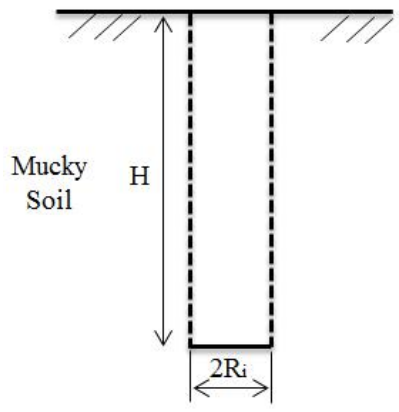

Before cavity expansion

The analysis of the cavity expansion theory ${ }^{3}$ was based on the following assumptions: (1) the soil mass is an ideal, homogeneous, and isotropic elastic plastic body; (2) the small cavity expands in an infinite soil mass; (3) the soil yield criterion is the Mohr-Coulomb yield criterion; (4) the soil pressure of the cavity wall is static before the expansion; and (5) the sand pile is made of pure sand without cohesive force, and the yield deformation is not considered.

\subsection{Basic Equations}

The radial stress of the soil around the pile was denoted by $\sigma_{r}$, the circumferential stress was 

strain axial symmetry. The polar coordinates were used without considering the initial stress field, and the equilibrium differential equation was obtained as follows:

$$
\frac{d \sigma_{r}}{d r}+\frac{\sigma_{r}-\sigma_{\theta}}{r}=0
$$

113 Geometric equation is

$$
\varepsilon_{r}=\frac{d u_{r}}{d r}
$$

In the elastic deformation phase, the stress function $\psi$ was assumed to be only a function of

116 the radial coordinate $\mathrm{r}$ :

$$
\psi=L \ln r
$$

where $r$ is the radial coordinate, and L represents the boundary constant.

119 During the plastic deformation stage, the Mohr-Coulomb yield criterion was used:

$$
\left(\sigma_{r}-\sigma_{\theta}\right)=\left(\sigma_{r}+\sigma_{\theta}\right) \sin \varphi+2 c \cos \varphi
$$

\subsection{Solution of Displacement Field and Stress Field in the Surrounding Soil Layer}

122 In the elastic zone, the stress and strain were defined by the following equations:

$$
\varepsilon_{r}=\frac{1-v^{2}}{E}\left(\sigma_{r}-\frac{v}{1-v} \sigma_{\theta}\right)
$$

$$
\sigma_{r}+\sigma_{\theta}=0
$$

$$
\sigma_{r}=-\sigma_{\theta}=\frac{R_{i}^{2} p}{r^{2}}
$$

The displacement of the soil around the pile should satisfied the following equation:

$$
u=\frac{(1+v) R_{i}^{2}}{E} \frac{p}{r}=\frac{(1+v)}{E} r \sigma_{r},
$$

128 where $r$ is the radial coordinate, $u_{r}$ is the radial displacement, $R_{i}$ is the initial radius of the 
cavity, $p$ is the initial radial stress, $\mathrm{E}$ is the elastic modulus, and $v$ is Poisson's ratio.

130 Based on Equation (4) and Equation (1), the following equation was obtained by solving the 131 equilibrium differential equation:

$$
\sigma_{r}=\left(p_{u}+\operatorname{Cctg} \varphi\right)\left(\frac{R_{u}}{r}\right)^{\frac{2 \sin \varphi}{1+\sin \varphi}}-\operatorname{Cctg} \varphi
$$

By satisfying Equations (4) and (6) under the common boundary conditions of elasticity and

134 plasticity, the following equation was obtained:

$$
\sigma_{p}=\sigma_{r}=C \cos \varphi
$$

On the boundary between the elastic zone and the plastic zone, the displacement of the overall expansion of the plastic zone was obtained on the basis of Equation (8):

$$
u_{p}=\frac{(1+v)}{E} R_{p} \sigma_{p} .
$$

The radial stress near the boundary of the plastic zone was expressed as follows: was obtained:

$$
\sigma_{p}=\left(p_{u}+\operatorname{Cctg} \varphi\right)\left(\frac{R_{u}}{R_{p}}\right)^{\frac{2 \sin \varphi}{1+\sin \varphi}}-\operatorname{Cctg} \varphi .
$$

$$
p_{u}=C\left[\frac{\cos \varphi+\operatorname{ctg} \varphi}{\left(\frac{R_{u}}{R_{p}}\right)^{\frac{2 \sin \varphi}{1+\sin \varphi}}}-\operatorname{ctg} \varphi\right] .
$$

144 The volume change after the expansion of the cylindrical cavity is equal to the volume change 145 of the elastic zone and that of the plastic zone, and the following equation was obtained:

$$
\pi R_{u}^{2}-\pi R_{i}^{2}=\pi R_{p}^{2}-\pi\left(R_{p}-u_{p}\right)^{2}+\pi\left(R_{p}^{2}-R_{u}^{2}\right) \Delta
$$

147 where $R_{p}$ is the maximum radius of the plastic zone, $R_{u}$ is the final radius of the cavity, $u_{p}$ is 
the overall displacement of the plastic zone, and $\Delta$ is the average volumetric strain of the plastic zone.

It was considered that the radius of the initial cavity approaches zero, so it was simplified as $R_{i}^{2} \rightarrow 0$, and the overall displacement of the plastic zone boundary is relatively small.

In the above calculation, the initial stress field was not considered. For the mucky soil, the stress increase, $\sigma_{p}=C \cos \varphi$, which made the soil enter the plastic state very small. To satisfy the condition that soil easily enters the plastic state, the influence range of the plastic zone needs to be large so that the overall displacement of the plastic zone boundary can be considered relatively small and simplified as follows: $u_{p}{ }^{2} \rightarrow 0$. The following equation was obtained:

$$
1+\Delta=2 u_{p} \frac{R_{p}}{R_{u}{ }^{2}}+\frac{R_{p}{ }^{2}}{R_{u}{ }^{2}} \Delta
$$

For mucky soil, the pore water pressure was difficult to dissipate during the construction of the sand pile, the soil particles were uncompressible, and the amount of compression in the plastic zone was negligible, so the following equation was obtained:

$$
1=2 u_{p} \frac{R_{p}}{R_{u}{ }^{2}}
$$

The following equation was obtained based on Equations (10), (11), and (16):

$$
\frac{R_{p}}{R_{u}}=\sqrt{\frac{E}{2(1+v) C \cos \varphi}} .
$$

164 By substituting Equation (17) into Equation (13), the following equation was obtained:

$$
p_{u}=C\left[(\cos \varphi+\operatorname{ctg} \varphi)\left(\frac{E}{2(1+v) C \cos \varphi}\right)^{\frac{\sin \varphi}{1+\sin \varphi}}-\operatorname{ctg} \varphi\right] .
$$

The equation of stress and path can be obtained:

$$
\sigma_{r}=C\left[(\cos \varphi+\operatorname{ctg} \varphi)\left(\frac{E}{2(1+v) C \cos \varphi}\right)^{\frac{\sin \varphi}{1+\sin \varphi}}\left(\frac{R_{u}}{r}\right)^{\frac{2 \sin \varphi}{1+\sin \varphi}}-\operatorname{ctg} \varphi\right] .
$$

9 Authors: Peishuai Chen, Huiwu Luo, Dejie Li, Enlong Liu, Benliang Yang. Corresponding author: Peishuai Chen. (email: ps.chen@qq.com) 


\subsection{Increase of Additional Stress Induced by Sand Pile Construction}

169 When the sand piles are arranged in the shape of an equilateral triangle whose side length is $S$, 170 interactions occur between the sand piles, where $d_{e}$ is the influence range of a single sand pile, 171 and $r_{e}$ is the influence radius. It can be seen from Equation (19) that the radial stress decreases 172 with increased $r$. For safety considerations in engineering design, the increase in the additional 173 stress of the soil around the pile caused by the cavity expansion of a single sand pile has a 174 uniform distribution. The value is the additional stress at the boundary of the single pile; that is, 175 the average additional stress increase in the entire plastic zone is $\sigma_{e q}$.

$$
\sigma_{r}=C\left[(\cos \varphi+\operatorname{ctg} \varphi)\left(\frac{E}{2(1+v) C \cos \varphi}\right)^{\frac{\sin \varphi}{1+\sin \varphi}}\left(\frac{R_{u}}{r_{e}}\right)^{\frac{2 \sin \varphi}{1+\sin \varphi}}-\operatorname{ctg} \varphi\right] .
$$

The following equation was obtained:

$$
d_{e}=1.05 s
$$

The replacement rate of the sand pile is represented by $m$, which can be expressed as follows:

$$
m=\frac{d^{2}}{d_{e}^{2}}=\left(\frac{R_{u}}{1.05 r_{e}}\right)^{2}
$$

By substituting Equation (22) into Equation (20), the following equation was obtained:

$$
\sigma_{e q}=C\left[(\cos \varphi+\operatorname{ctg} \varphi)\left(\frac{0.551 m E}{(1+v) C \cos \varphi}\right)^{\frac{\sin \varphi}{1+\sin \varphi}}-\operatorname{ctg} \varphi\right] .
$$

\section{Increase of Effective Stress during the Load Phase}

184 Open caisson foundations are often used in large-scale bridge foundation construction. Since the caisson is a temporary project during the pre-fabrication and sinking process, large settlement of the caisson or controllable inclination are allowed. Moreover, the construction of the caisson in the pre-fabrication process takes a relatively long time, and the additional stress is gradually converted into effective stress, so the improvement of the bearing capacity of the foundation 
cannot be ignored.

\subsection{Calculation of Influence Depth}

The distribution of the additional stress of the foundation can be expressed by the contour line. If the additional stress $\sigma_{z}=0.1 p$, the influence of the additional stress is negligible, whereas for the strip load, the contour line of the additional stress passes below the center approximately ${ }^{15}$ when $z \approx 6 B$. Therefore, the depth for the strip load is $H=6 B$.

\subsection{Calculation of Degree of consolidation}

The improved Jun Takagi method ${ }^{16}$ was used to calculate the degree of consolidation, and the equation is as follows:

$$
\overline{U_{t}}=\sum_{i=1}^{n} \frac{\dot{q}_{i}}{\sum \Delta p}\left[\left(T_{i}-T_{i-1}\right)-\frac{\alpha}{\beta} e^{-\beta t}\left(e^{\beta T_{i}}-e^{\beta T_{i-1}}\right)\right],
$$

where $\bar{U}_{t}$ is the average degree of consolidation of the foundation within the depth range calculated within a given time of $t, \dot{q}_{i}(\mathrm{kPa} / \mathrm{d})$ is the loading rate of the $\mathrm{i}$-th load, $\sum \Delta p \quad(\mathrm{kPa})$ is the accumulated value of the load at each level, $T_{i}, T_{i-1}$ (d) are the starting and ending times of the i-th load, and $\alpha, \beta$ are the parameters of the consolidated drainage conditions of the foundation soil.

Parameters $\alpha, \beta$ can be expressed as follows:

$$
\alpha=\frac{8}{\pi^{2}}
$$

$$
\beta=\frac{8 c_{h}}{F_{n} d_{e}^{2}}+\frac{\pi^{2} c_{v}}{4 H^{2}}
$$




$$
F_{n}=\frac{n^{2}}{n^{2}-1} \ln (n)-\frac{3 n^{2}-1}{4 n^{2}}
$$

\subsection{Relationship between Effective Stress and Total Stress during the Sand Pile}

\section{$210 \quad$ Construction}

211 The relationship between the average effective stress of soil and total stress can be expressed by 212 the following equation:

$$
U=\frac{p_{z t}^{\prime}}{p_{z \infty}^{\prime}}=\frac{p^{\prime}}{p}
$$

where $p_{z t}^{\prime}\left(p^{\prime}\right)$ represents the effective stress at time $t$, and $p_{z \infty}^{\prime}(p)$ stands for the effective stress at the time of complete consolidation.

$$
p=\frac{\sigma_{1}+\sigma_{2}+\sigma_{3}}{3}
$$

The soil is isotropic, and the equation of calculating the static soil pressure is as follows:

$$
\sigma_{1}=\gamma H+\sum \Delta p_{z}
$$

where $H$ is the buried depth, $K_{0}$ is the static soil pressure coefficient, $p_{z}$ is the additional stress, and $\gamma$ is the dead load of the soil.

When no load was applied, or the applied load was not converted into effective stress, the

223 following equation was given:

$$
\sum \Delta p_{z}=0
$$

$$
\sigma_{e q}=0
$$

$$
p=\frac{\left(1+2 K_{0}\right) \gamma H}{3}
$$

After sand pile construction was completed, the total stress with additional load applied could 
be expressed as follows:

$$
p=\frac{\left(1+2 K_{0}\right) \gamma H+\sum \Delta p_{z}+2 \sigma_{e q}}{3} .
$$

4. Relationship between Effective Stress and Bearing Capacity of the Foundation

\subsection{Relationship between Effective Stress and Water Content}

The groundwater level in the coastal area was relatively high and the stratum had been located

$$
S_{r}=\frac{w G_{s}}{e}
$$

236 that is, $e=w G_{s}$.

237 For normal consolidated soi,

$$
e_{0}-e_{c}+\lambda \ln p^{\prime}=0
$$

Equation (38) can be changed to the following equation:

$$
e_{0}-e_{c}+\lambda \ln U p=0
$$

where $e_{c}$ is the reference void ratio, $e_{0}$ is the void ratio on the normal consolidation curve, the average total stress.

\subsection{Relationship between Bearing Capacity of the Foundation and Water Content}


Table 1 Basic bearing capacity of the soft soil foundation

\begin{tabular}{|c|c|c|c|c|c|c|c|}
\hline Natural water content (\%) & 36 & 40 & 45 & 50 & 55 & 65 & 75 \\
\hline Basic bearing capacity(kPa) & 100 & 90 & 80 & 70 & 60 & 50 & 40 \\
\hline
\end{tabular}

The average effective stress increase can be obtained based on the external load, the size of the sand pile, and the buried depth of the soil layer, and, thereby, the change of the void ratio and the water content can be obtained. Since the water content of the soft soil foundation is well correlated with the bearing capacity of the foundation, the increase of the bearing capacity of the foundation can be obtained based on the water content, providing a basis for the design

256 calculation of the sand pile composite foundation.

\section{Engineering Example}

The calculation method proposed in this study was applied to the south anchor foundation of Wenzhou Oujiang Estuary Bridge, which is the world's most thick mucky soil layer of super large land caisson. The caisson foundation was applied to the south anchor, the plane dimension of the caisson was $70 \times 63 \mathrm{~m}$, the total height of the caisson was $67.5 \mathrm{~m}$, the standard wall thickness was $2.0 \mathrm{~m}$, the partition wall was $1.2 \mathrm{~m}$ thick and $8 \mathrm{~m}$ high, the common partition wall was $6.1 \mathrm{~m}$ high, and thirty $10.84 \times 10 \mathrm{~m}$ rectangular well holes were set. The caisson was located in a deep mucky soil layer with an average thickness of $36 \mathrm{~m}$ and a local thickness of $40 \mathrm{~m}$.

\subsection{Geology and Hydrogeology}

266 Table 2 shows the simplification and parameters of the soil layer. As for the mucky clay in the surface layer (Number (2) 1 ), if the pre-consolidation pressure is greater than the gravity of the soil, the mucky clay should be judged as slightly over-consolidated soil, and the slope of the compression curve $k=0.064$ can be directly used in the calculation, so the average effective pre-consolidation pressure is $P_{\mathrm{c}}=85.6 \mathrm{kPa}$. If the average effective stress load is less than the average effective pre-consolidation pressure, the slope $\kappa$ should be used. When the average 
272 effective stress load is greater than the average effective pre-consolidation pressure, the slope $\lambda$

273 ought to be used.

Table 2 Physico-mechanical properties of caisson soil

\begin{tabular}{|c|c|c|c|c|c|c|c|c|}
\hline No. & $\begin{array}{l}\text { Soil } \\
\text { layer }\end{array}$ & $\begin{array}{c}\text { Thickness } \\
\text { (m) }\end{array}$ & $\mathrm{Pc}(\mathrm{kPa})$ & $\lambda$ & $\begin{array}{l}\text { Compression } \\
\text { modulus (MPa) }\end{array}$ & $\begin{array}{l}\text { Permeability coefficient } \\
\qquad\left(10^{-6} \mathrm{~cm} / \mathrm{s}\right)\end{array}$ & $\begin{array}{l}\text { Bearing capacity } \\
\text { Eigenvalue }(\mathrm{kPa})\end{array}$ & $\begin{array}{c}\text { Side friction } \\
\qquad(\mathrm{kPa})\end{array}$ \\
\hline- & Sand bed & 3 & - & - & - & - & 300 & 20 \\
\hline (2) 1 & $\begin{array}{l}\text { Mucky } \\
\text { clay }\end{array}$ & 12.73 & 135.1 & 0.32 & 2.44 & 0.13 & 60 & 12 \\
\hline (2) 3 & Silt & 15 & 91.27 & 0.58 & 1.93 & 0.22 & 55 & 10 \\
\hline (3) 3 & $\begin{array}{l}\text { Mucky } \\
\text { clay }\end{array}$ & 5.22 & 150.8 & 0.40 & 2.18 & 0.40 & 60 & 15 \\
\hline
\end{tabular}

The mechanical parameters of the soil layer are shown in Table 3.

Table 3 Physical parameters of the soil layer

\begin{tabular}{|c|c|c|c|c|c|c|c|}
\hline Layer No. & Name & $w(\%)$ & $e$ & $\mathrm{G}_{\mathrm{s}}$ & $\mathrm{C}_{\mathrm{cu}}(\mathrm{kPa})$ & $\Phi_{\mathrm{cu}}\left({ }^{\circ}\right)$ & $\mathrm{K}_{0}$ \\
\hline$(2)_{1}$ & Mucky clay & 47.2 & 1.312 & 2.72 & 16.3 & 14.9 & 0.45 \\
\hline$(2)_{3}$ & Silt & 59.1 & 1.669 & 2.75 & 12.4 & 14 & 0.41 \\
\hline$(3)_{2}$ & Mucky clay & 47.8 & 1.342 & 2.71 & 14.5 & 16.1 & 0.5 \\
\hline
\end{tabular}

\subsection{Calculation of Replacement Rate of the Sand Pile}

278 To simplify the calculation process, it was assumed that the excess pore pressure induced by the

279 additional load had completely dissipated. The increase of the additional stress induced during

280 the sand pile construction is inseparable from the replacement rate of the sand pile. The

281 replacement rate can be preset and substituted into Equation (23), and the replacement rate can be

282 obtained. If the error between the preset replacement rate and the calculated replacement rate is

283 less than $5 \%$, the calculated replacement ratio is the acceptable replacement rate. In this study, the

284 replacement rate was assumed to be $m=0.36$.

285 The relationships between the loads applied to the foundation and time are shown in Figures 


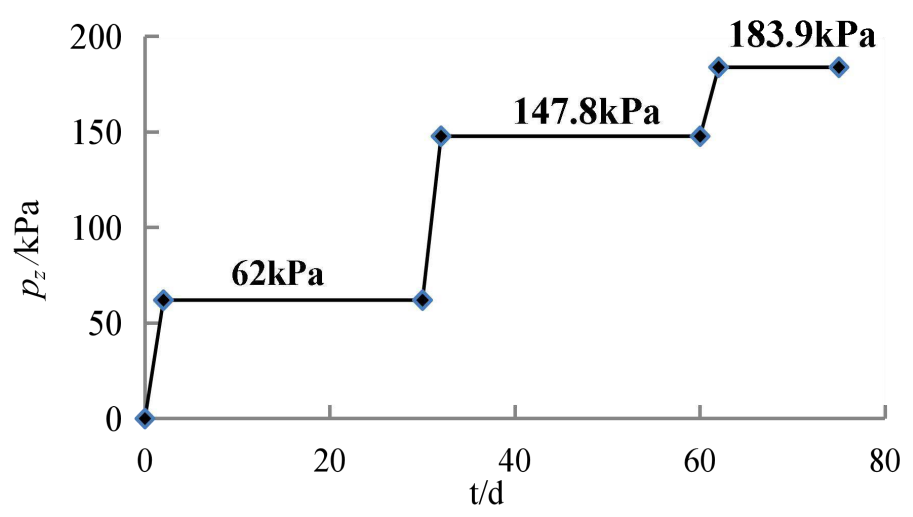

Fig. 3 Loading process of the caisson in Sections 1-3

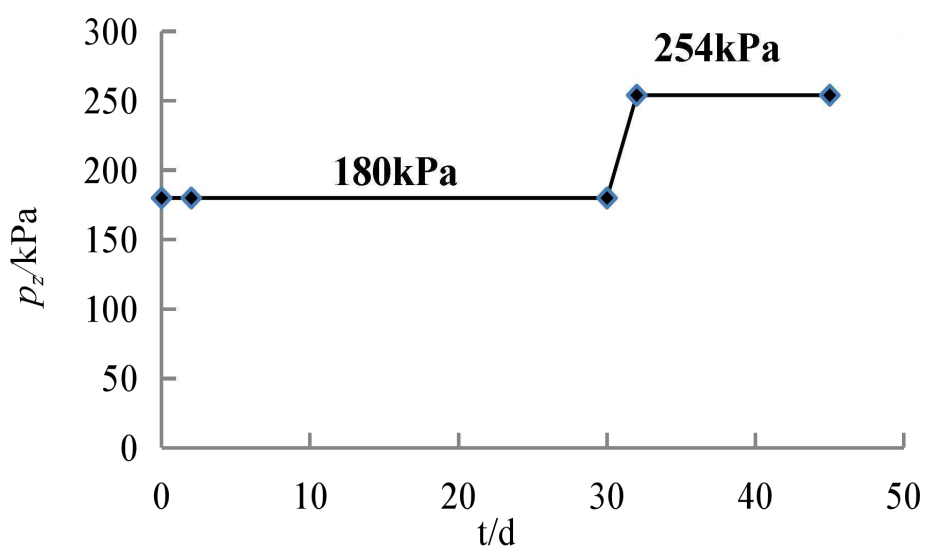

289

Fig. 4 Loading process of the caisson in Sections 4-5

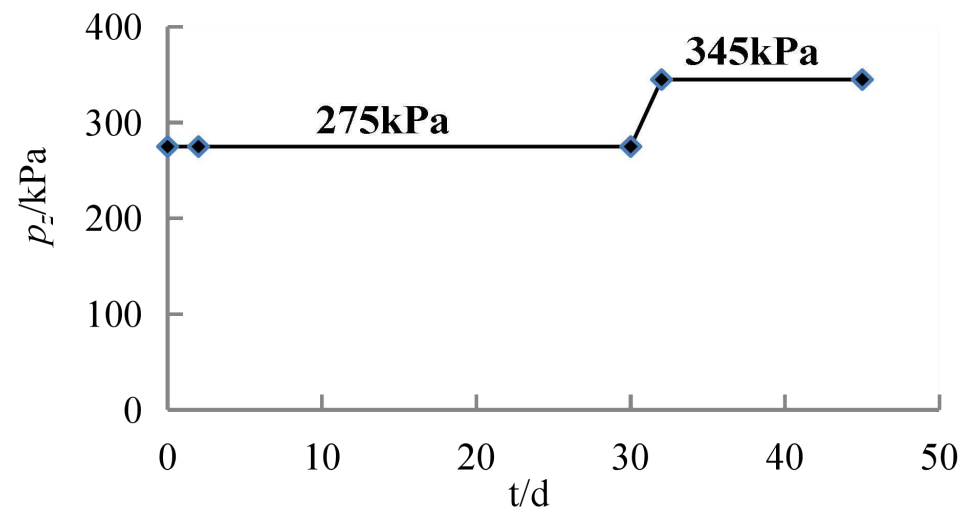




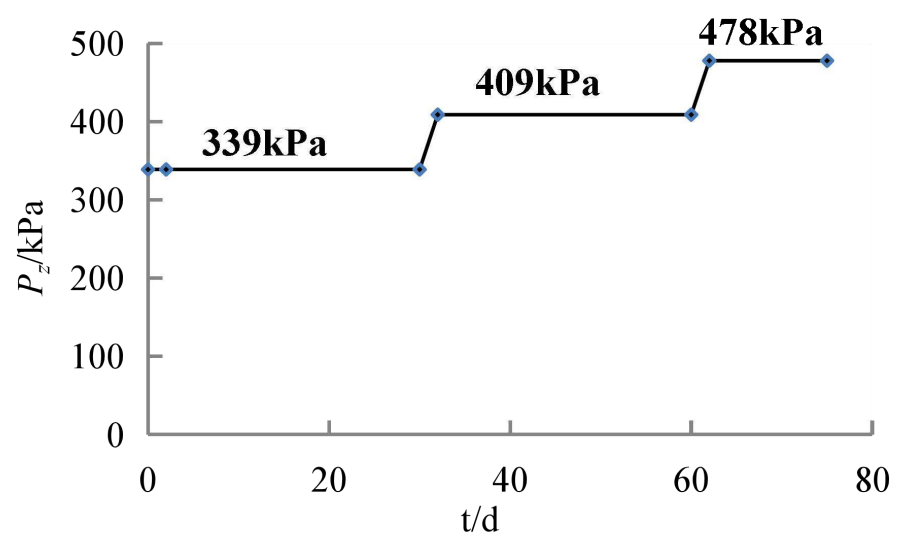

Fig. 6 Loading process of the caisson Sections 8-10

295 Table 4 shows the calculation results.

Table 4 Change in water content after dissipation of pore pressure

\begin{tabular}{|c|c|c|c|c|c|}
\hline Loading stage & $\begin{array}{c}\text { Original average } \\
\text { effective ground stress } \\
(\mathrm{kPa})\end{array}$ & $\begin{array}{c}\text { Average effective ground } \\
\text { stress after full consolidation } \\
\text { of soil (kPa) }\end{array}$ & $e$ & $w(\%)$ & Note \\
\hline $\begin{array}{l}\text { Sections 1-3 } \\
\text { of the caisson }\end{array}$ & 29.1 & 132.3 & 1.11 & 40.8 & Original ground \\
\hline $\begin{array}{l}\text { Sections 4-5 } \\
\text { of the caisson }\end{array}$ & 31.7 & 153.9 & 1.06 & 39.0 & $\begin{array}{c}\text { Digging at a depth of 5 } \\
\text { m with water injected }\end{array}$ \\
\hline $\begin{array}{l}\text { Sections 6-7 } \\
\text { of the caisson }\end{array}$ & 91 & 219.1 & 1.16 & 42.2 & $\begin{array}{c}\text { Digging at a depth of } \\
15 \text { m with water } \\
\text { injected }\end{array}$ \\
\hline $\begin{array}{l}\text { Sections 8-10 } \\
\text { of the caisson }\end{array}$ & 167 & 322.4 & 1.08 & 40.4 & $\begin{array}{c}\text { Digging at a depth of } \\
27 \text { m with water } \\
\text { injected }\end{array}$ \\
\hline
\end{tabular}

The bearing capacity of the foundation was calculated according to the water content (Table 5).

298 The bearing capacity of the sand pile was expressed as follows ${ }^{18}$ :

$$
k=\frac{20.8 C_{u}}{K},
$$

300 where $C_{u}$ represents cohesion, and $K$ is the safety factor, which is recommended to be 1.05. 
The equation of calculating the bearing capacity of the composite foundation ${ }^{19}$ is as follows:

$$
m=\frac{f_{s p k}-f_{s k}}{f_{p k}-f_{s k}} .
$$

Then, the replacement rate of the sand pile was obtained, and the calculation results are shown

\section{Table 5 Calculation of the replacement rate}

\begin{tabular}{|l|c|c|c|c|}
\hline Loading stage & $\begin{array}{c}\text { Bearing capacity eigenvalue of } \\
\text { the foundation needed by the } \\
\text { base }(\mathrm{kPa})\end{array}$ & $\begin{array}{c}\text { Bearing capacity } \\
\text { eigenvalue of the sand } \\
\text { pile }(\mathrm{kPa})\end{array}$ & $\begin{array}{c}\text { Bearing capacity eigenvalue } \\
\text { calculated by considering the } \\
\text { consolidation }(\mathrm{kPa})\end{array}$ & $\begin{array}{c}\text { Replacement } \\
\text { rate, } m\end{array}$ \\
\hline Sections 1-3 \\
of the caisson
\end{tabular}

The calculated pile-soil stress ratio was between 2.8 and 3.6, which is in accordance with the

308 undisturbed soil is high and the value is large ${ }^{19}$.

\subsection{Design of Sand Pile and Verification of Degree of consolidation}

\section{$310 \quad$ 5.3.1 Design of Sand Pile}

311 The replacement rate of the sand piles was set as $m=0.36$, and the sand piles were arranged in the

312 shape of a regular triangle. The diameter of each sand pile was $0.6 \mathrm{~m}$, and the space between the 313 sand piles was $0.95 \mathrm{~m}$. The bearing capacity of the foundation, calculated according to Equation 314 (41), is shown in Table 6. 
Table 6 Bearing capacity eigenvalue after foundation treatment

\begin{tabular}{|c|c|c|c|c|}
\hline Loading stage & $\begin{array}{c}\text { Bearing capacity } \\
\text { eigenvalue of the sand } \\
\text { pile (kPa) }\end{array}$ & $\begin{array}{c}\text { Bearing capacity eigenvalue } \\
\text { calculated by considering the } \\
\text { consolidation (kPa) }\end{array}$ & $\begin{array}{c}\text { Replacement } \\
\text { rate, } m\end{array}$ & $\begin{array}{c}\text { Bearing capacity } \\
\text { eigenvalue of the } \\
\text { foundation (kPa) }\end{array}$ \\
\hline $\begin{array}{c}\text { Sections 1-3 } \\
\text { of the caisson }\end{array}$ & 322 & 88.4 & 0.36 & 172.5 \\
\hline $\begin{array}{l}\text { Sections 4-5 } \\
\text { of the caisson }\end{array}$ & 322 & 92.5 & 0.36 & 175.1 \\
\hline $\begin{array}{l}\text { Sections 6-7 } \\
\text { of the caisson }\end{array}$ & 246 & 85.6 & 0.36 & 143.3 \\
\hline $\begin{array}{l}\text { Sections 8-10 } \\
\text { of the caisson }\end{array}$ & 287 & 89.2 & 0.36 & 160.4 \\
\hline
\end{tabular}

\subsubsection{Verification of Degree of Consolidation}

320 Upon the completion of the sand pile construction, the additional stress was gradually converted

321 into effective stress, and the pore pressure gradually disappeared. The degree of consolidation 322 was calculated within the influence depth range of the additional stress. The results show that all 323 the additional stress had been converted into effective stress before the caisson began to sink, and 324 the degree of consolidation reached $100 \%$.

\section{$325 \quad 5.4$ In-Situ Test}

326 The in-situ test was carried out at a randomly selected test point at the engineering site, and the 327 sand pile was constructed per the replacement rate $m=0.36$. Considering that the plate load test 328 can only reflect the bearing capacity of the shallow foundation, the in-situ test can only verify the 329 change of the bearing capacity of the foundation after the action of Sections 1-3 of the caisson. 330 Therefore, a load of $180 \mathrm{kPa}$ was applied to the composite foundation, and the bearing capacity 
of the composite foundation was tested after the soil pore pressure between the composite

332 foundation piles had completely dissipated(see Fig.7-8).

333

334

335

336

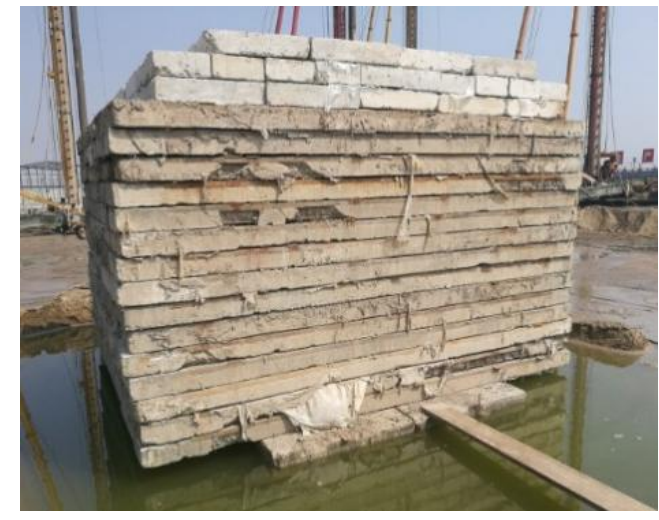

Fig. 7 On-site preloading

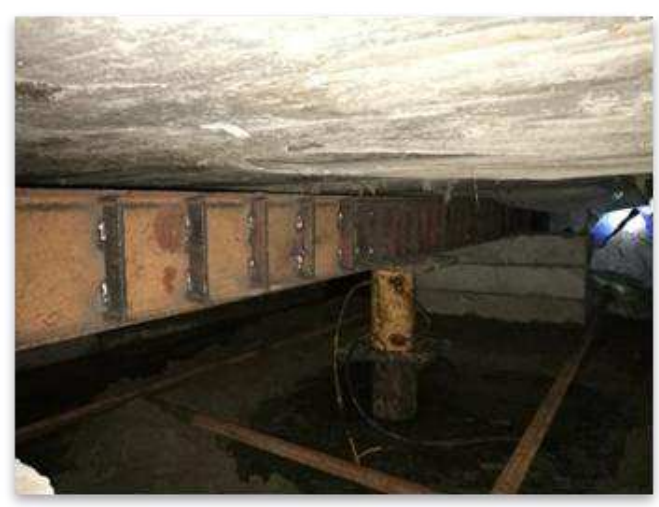

Fig. 8 On-site plate load test

The loading plate had a diameter of $1000 \mathrm{~mm}$, and the test was terminated ${ }^{16}$ once it was loaded to $60 \mathrm{~mm}$. The bearing capacity eigenvalue of the foundation was determined according to the relative deformation amount ${ }^{18}$. For soil layers with high compressibility, the maximum value of relative deformation did not exceed 0.015 , that is, when the settlement amount was $15 \mathrm{~mm}$, the corresponding load was $205 \mathrm{kPa}$, which is larger than the design value of $172.5 \mathrm{kPa}$ (see Fig.9). This shows that the above calculation method not only makes rational use of the improvement of foundation bearing capacity caused by consolidation but also has a large security coefficient, which can provide reference for similar projects. 


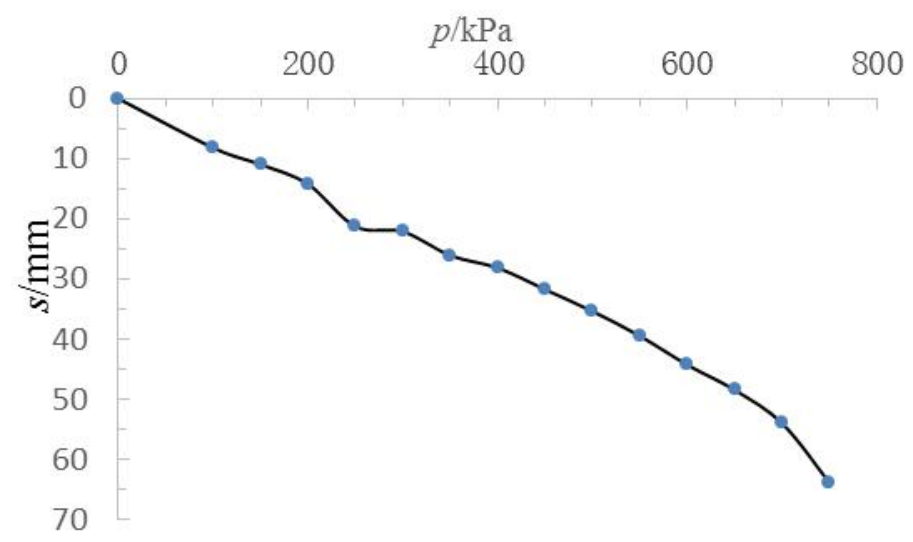

Fig. 9 P-S curve of the composite foundation

\section{Conclusions}

348 In this study, the reasons why the bearing capacity of the sand pile composite foundation is much

349 larger than the design value was explored. A feasible method of calculating the bearing capacity 350 of the foundation was proposed based on the cavity expansion theory, the e- $\mathrm{p}$ curve theory, and empirical data. This method can optimize the design of sand pile composite foundations.

The main contributions of this study are listed as follows:

(1) Cavity diameter expansion in sand pile construction was simplified into a planar problem,

354 the cavity expansion theory was used to simplify the calculation of the increase of the horizontal 355 stress of the soil between the piles caused by the sand compaction piles, and the expressions of 356 the change in displacement rate and horizontal stress were established.

(2) Considering the vertical effective stress increase caused by silt consolidation, the e-p curve was used to establish the relationship between the increase of the horizontal and vertical 359 effective stress and the void ratio.

(3) Based on the close relationship between the bearing capacity of the foundation in the 
363 established. According to this relationship, it was determined that the increase of the effective 364 stress caused an increase in the bearing capacity of the foundation.

365 For projects with long preloading or layered loading, under the premise of allowing large 366 foundation deformation, the increased bearing capacity of the foundation caused by sand pile 367 compaction construction and preloading can be fully considered to reduce the replacement rate 368 and lower the construction cost. 


\section{References}

1. Kelly R B, Houlsby G T, Byrne B. W. A comparison of field and laboratory tests of caisson foundations in sand and clay[J]. Ge' otechnique, 56(9): 617-626 (2006).

2. Butterfield, R.\&Banerjee, P. IK. Application of Electro-Osmosisto Soils. 1'art2, Civil Engineering Research Report, No. 31, Department of Civil Engineering, Southampton Unit, UR:709705 (1968).

3. Vesic A S. Expansion of cavities in infinite soil mass[J]. Journal of the soil Mechanics. 98(3):265-289 (1972).

4. Randolph, M. F, Carter, J. P. \& Wroth, C. P. Driven Piles in Clay the Effects o) rnstallation and Subsequent Consolidation Geotechnique. 29(4):361-393 (1979).

5. Yu HS, Houlsby GT. Finite cavity expansion in dilatants soils: loading analysis. Géotechnique, 41(2):173 - 183 (1991).

6. Collins I. F. Yu H S. Undrained cavity expansion in critical state soils[J]. International Journal for Numerical and. Analytical Methods in Geomechanics, 20(7):489-516 (1996).

7. Zhou Hang, Liu Hanlong, Yuan, Jingrong et al. A novel analytical approach for predicting the noncylindrical pile penetration-induced soil displacement in undrained soil by combining use of cavity expansion and strain path methods[J]. International Journal for Numerical and Analytical Methods in Geomechanics, 42:1270-1305 (2018).

8. Barron R. A. Consolidation of fine-grained soils by drain wells[J]. Traps. ASCE, (113):718-754 (1948).

9. Richart F. E. A Review of the Theories for Sand Drains[J]. ASCE proc., Soil Mechanics and Foundations, 83(3): 1301 (1957). 
10. Onoue A. Consolidation by vertical drains taking well resistance and smear into 393 consolidation [J].Soil and Foundations, 28(4):165-174 (1988).

394 11. Olson RE. Consolidation under time dependent loading [J].Journal of Geotechnical 395 engineering Division, Proceeding of ASCE, 103:55-60 (1977).

396 12. Lekha K R, Krishnaswamy N R. Basak PConsolidation of clay by sand drain under time 397 dependent loading[J].Journal of Geoenviron-Mental engineering, 124(1):91-94 (1998).

398 13. Yu H S. Plasticity and Geotechnics[M]. Springer Science Business Media (2006).

14. Meyerhof G G. Ultimate bearing capacity of footings on sand layer overlying clay[J].

400 Canadian Geotechnical Journal, 11: 223-229 (1974).

401 15. Braja M, Das. Principles of Geotechnical Properties of Soils, (Eighth Edition) Cengage 402 Learning (2012).

16. China Academy of Building Research. JGJ79-2012 Technical code for ground treatment 404 of buildings[S]. Beijing: China Architecture and Building Press (2011). and foundation of highway bridges and culverts[S]. Beijing: China Communications Press (2007).

18. Minister of housing and urban-rural development of the people's republic of china. 409 GB/T 50783 - 2012 Technical code for composite foundation[S]. Beijing: China Planning Press 410 (2012).

411 19. GONG Xiaonan. Handbook for foundation treatment [M]. Beijing: China Architecture 412 and Building Press (2008). 


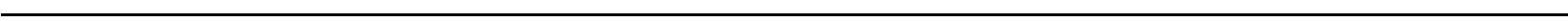




\section{Figures}

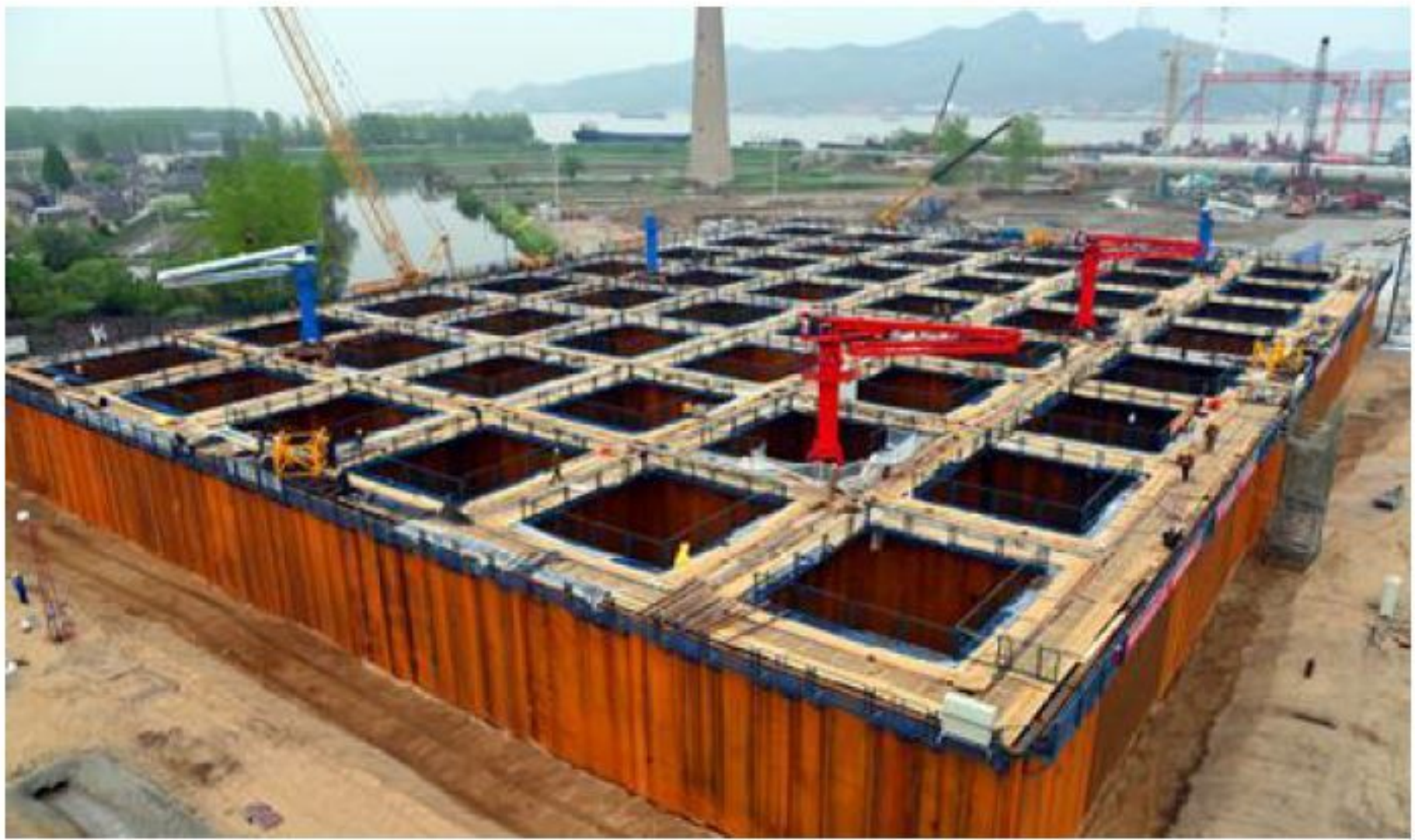

Figure 1

Wufeng mountain Yangtze river bridge's north anchorage caisson

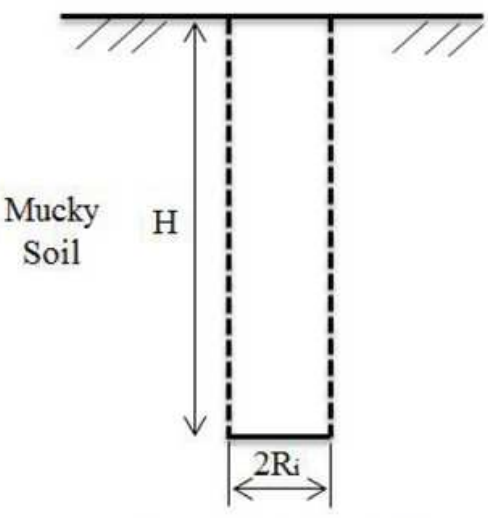

Before cavity expansion

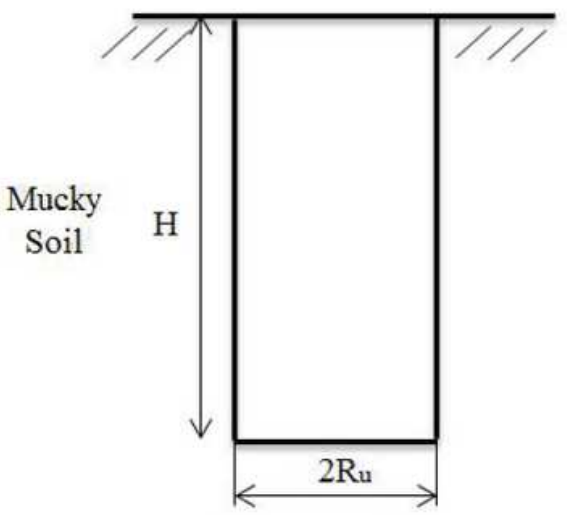

After cavity expansion
The elastic zone

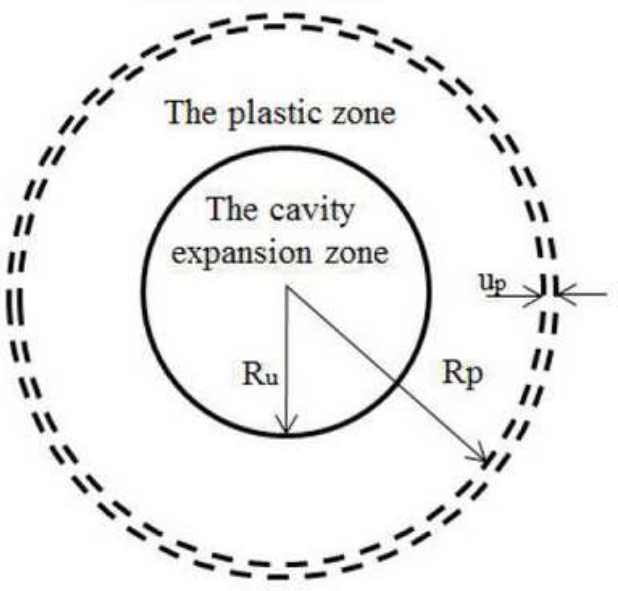

Figure 2

Cavity expansion model 


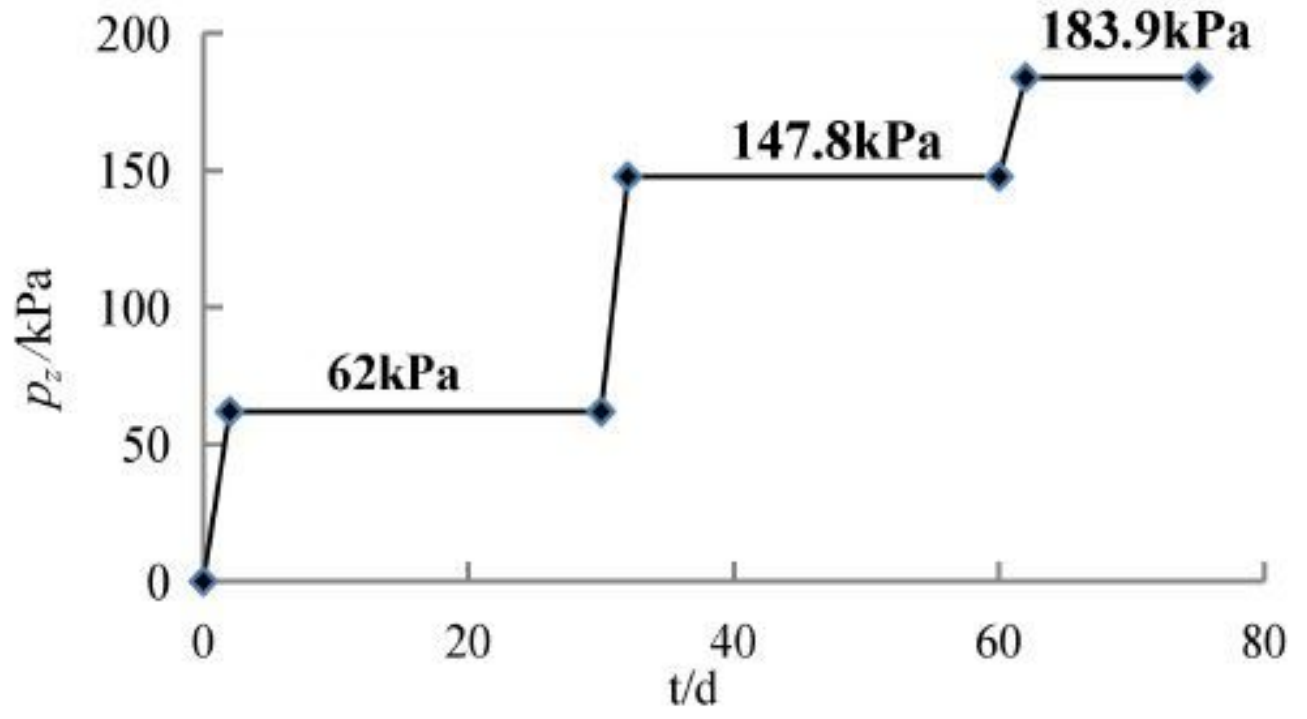

Figure 3

Loading process of the caisson in Sections 1-3

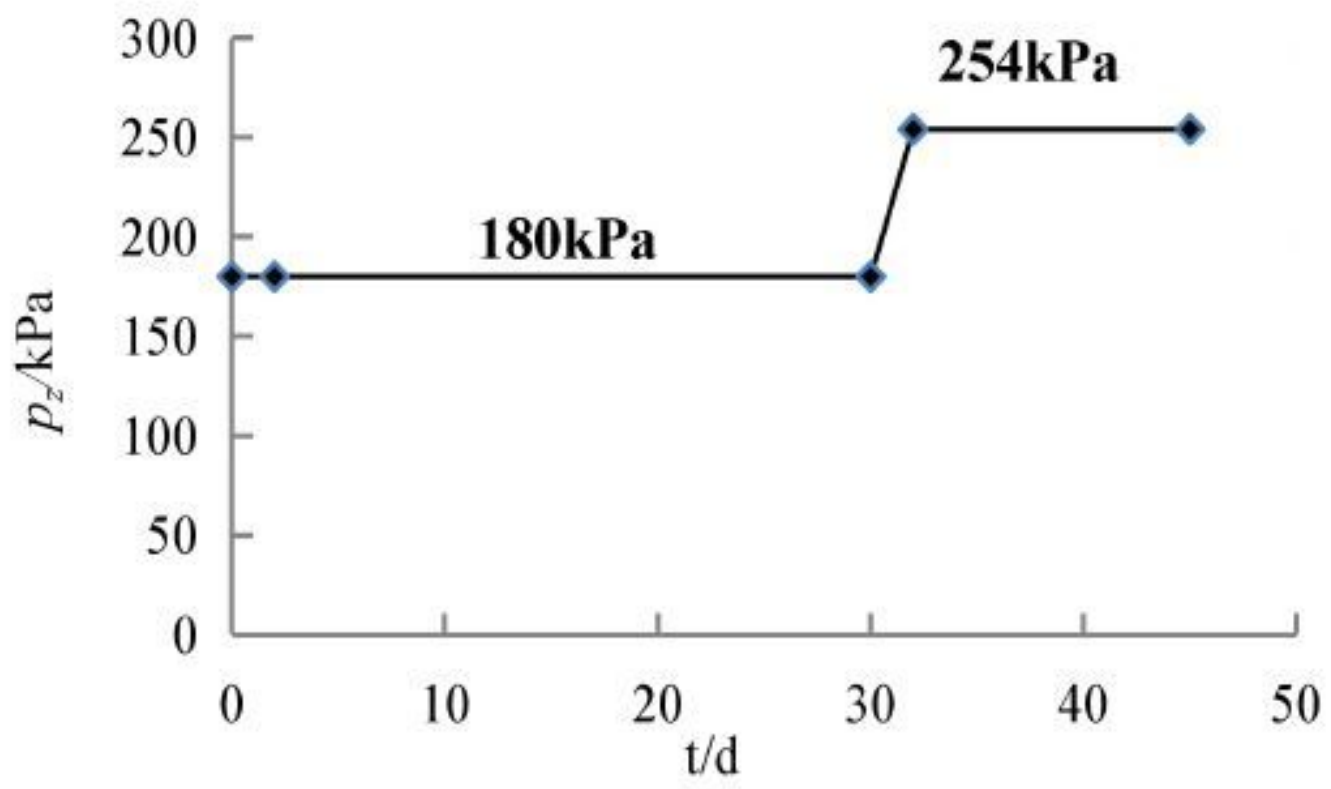

Figure 4

Loading process of the caisson in Sections 4-5 


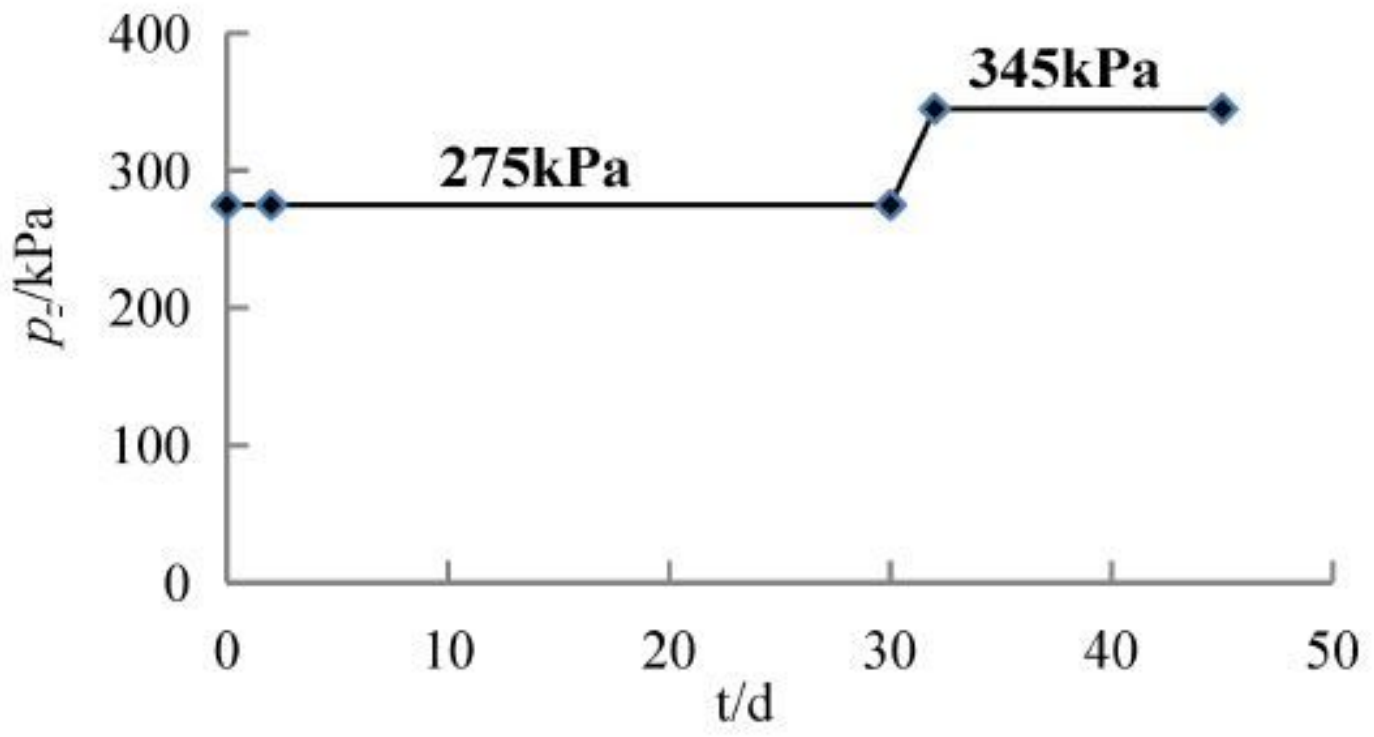

Figure 5

Loading process of the caisson in Sections 6-7

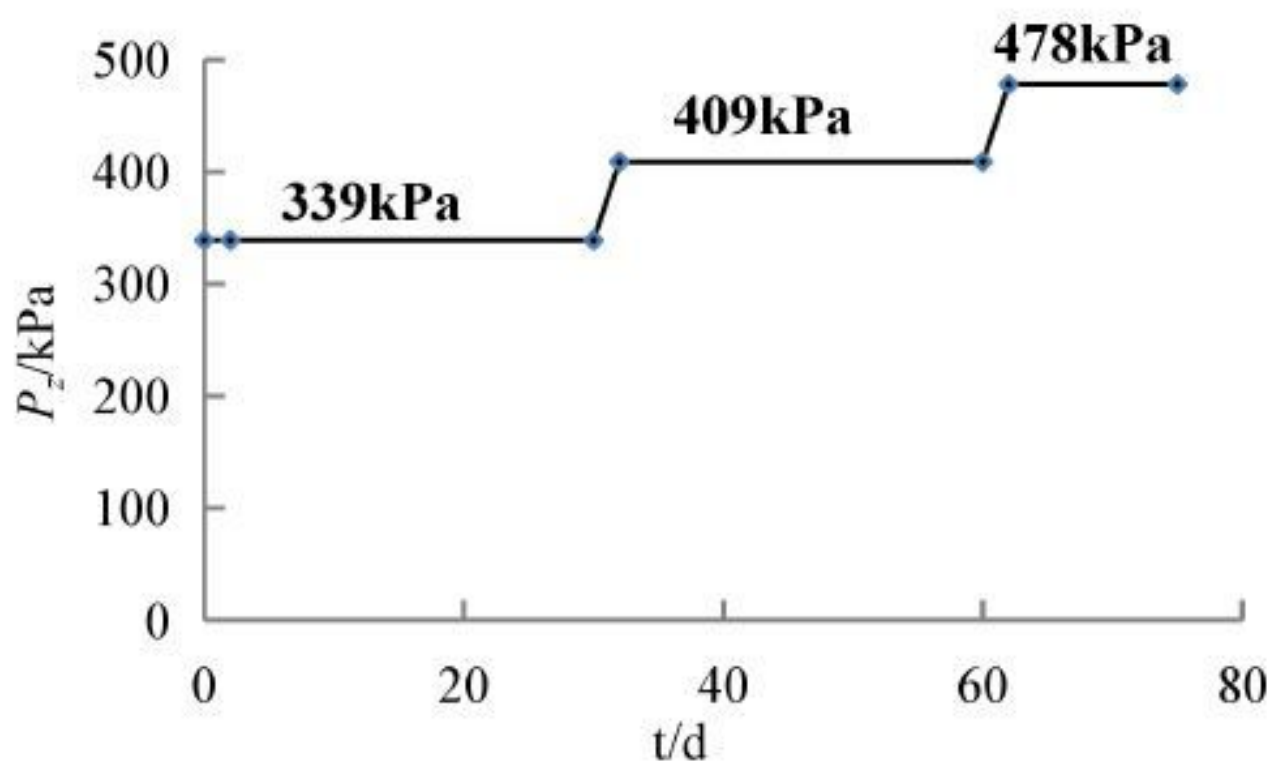

Figure 6

Loading process of the caisson Sections 8-10 


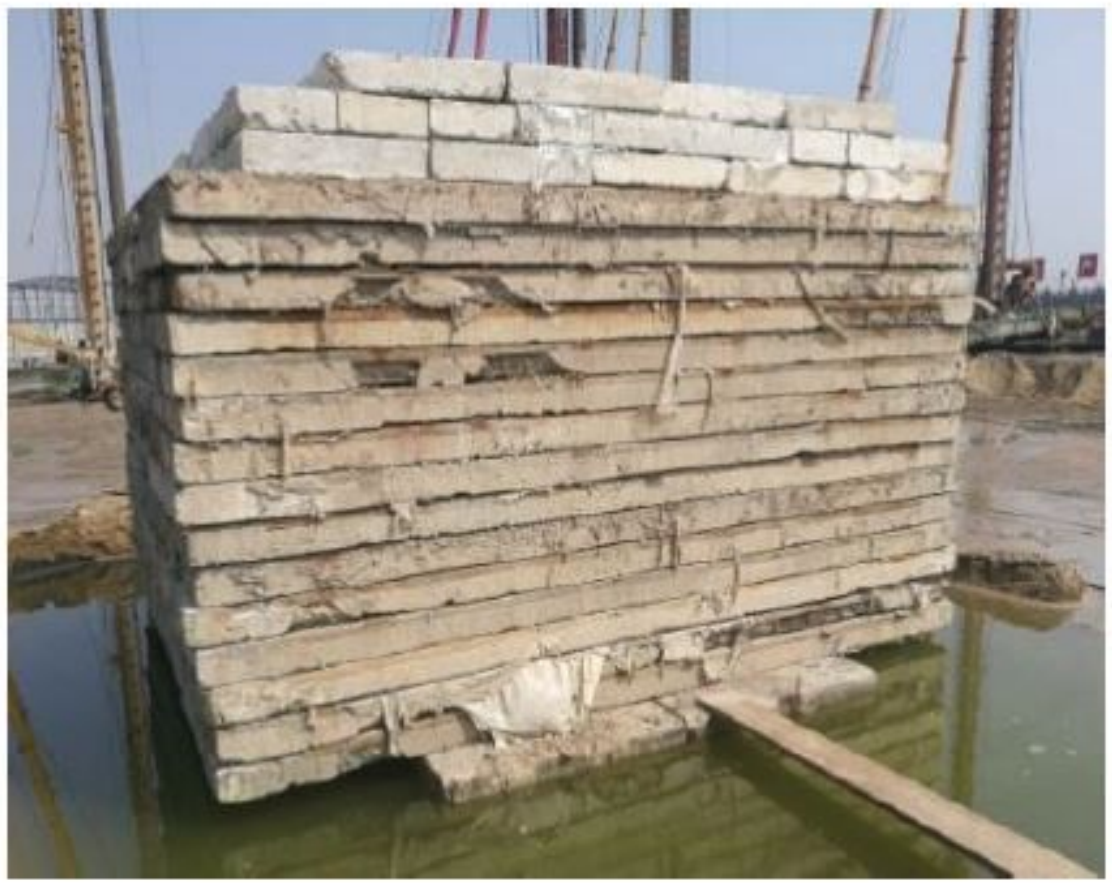

Figure 7

On-site preloading

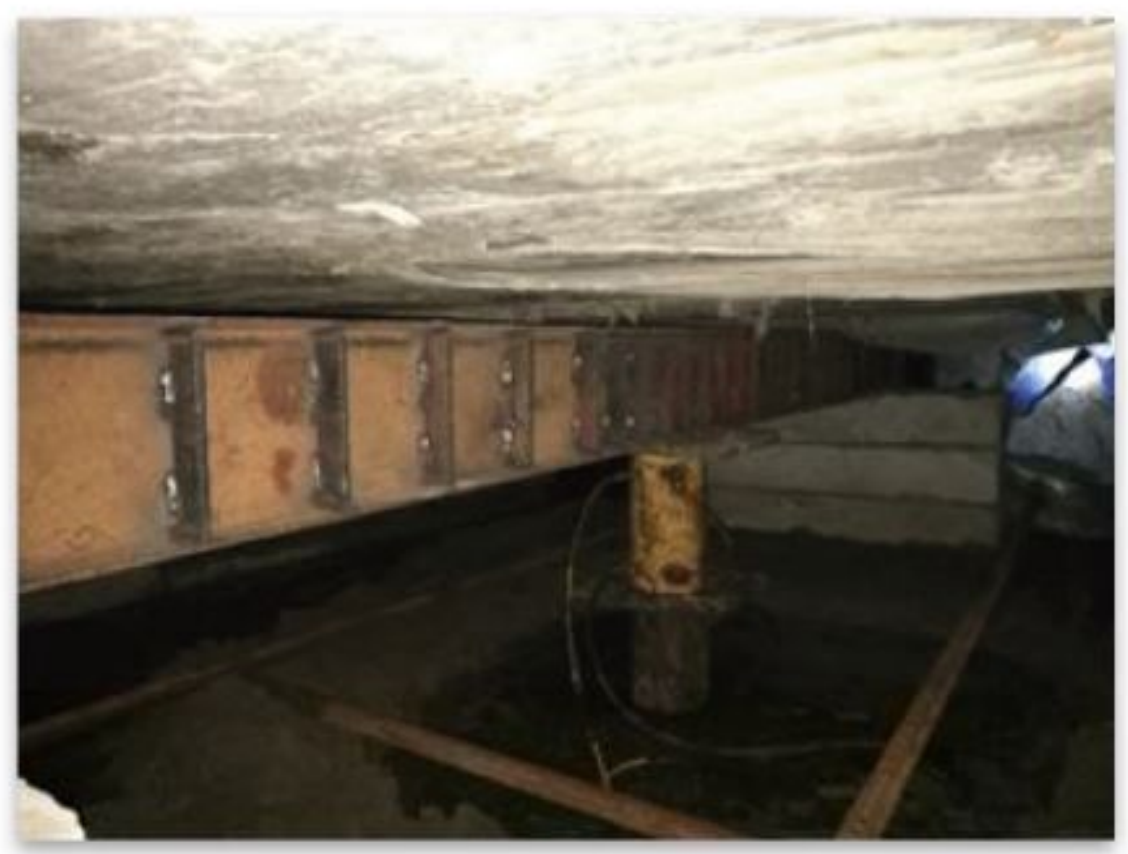

Figure 8

On-site plate load test 


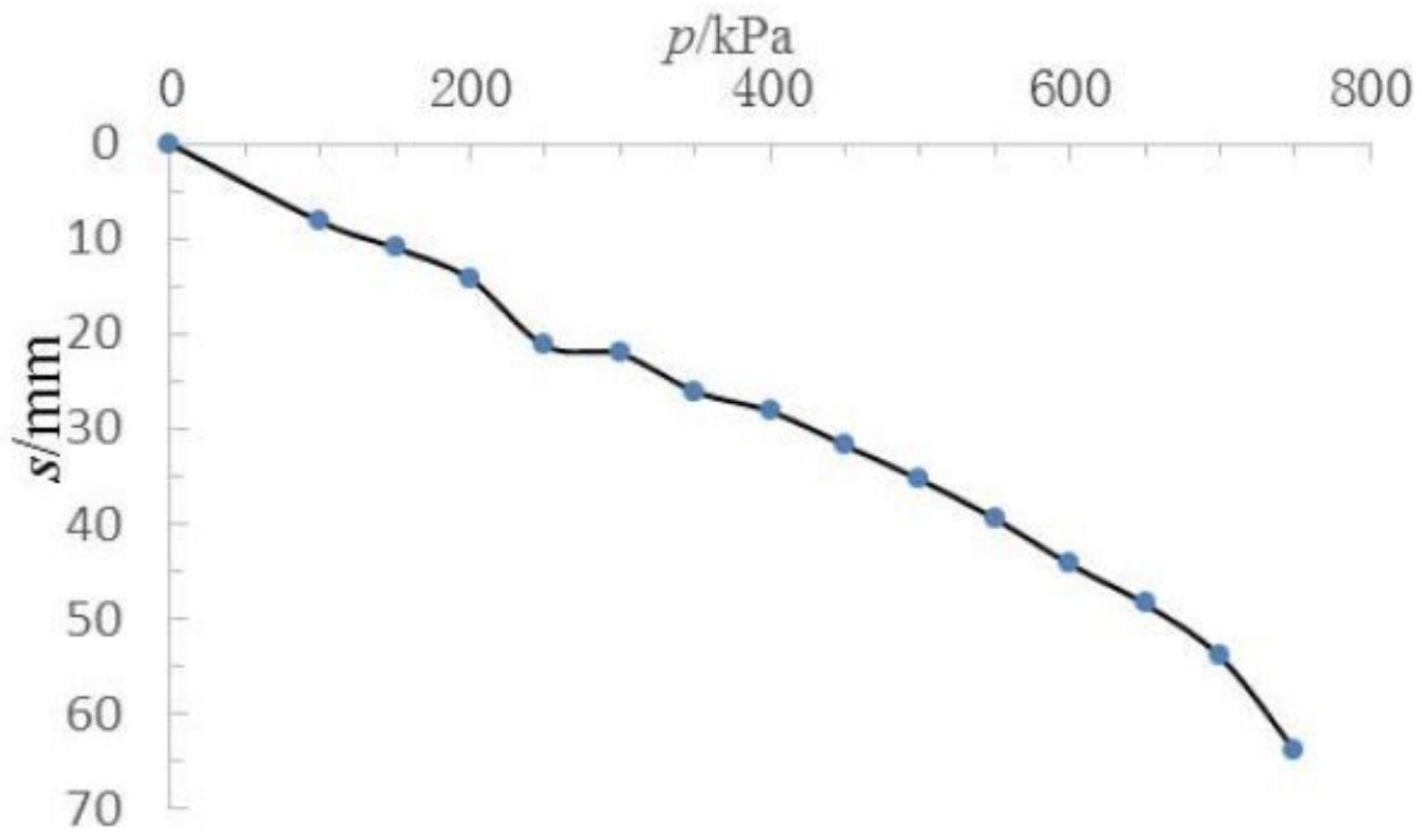

Figure 9

$\mathrm{P}-\mathrm{S}$ curve of the composite foundation 